\title{
Caracterização do consórcio coqueiro-bananeira no Perímetro Irrigado das Várzeas de Sousa, PB.
}

\author{
Isabelle da Costa Wanderley Alencar ${ }^{*}$, Pedro Vieira de Azevedo ${ }^{1}$
}

RESUMO: No município de Sousa, agricultores familiares do perímetro irrigado das Várzeas de Sousa (PIVAS) fazem consórcio do coqueiro-anão com a bananeira, aproveitando o espaçamento entre os coqueiros, visando uma produção mais constante e estável ao longo do tempo. A representatividade desses cultivos de alta demanda hídrica nessa localidade semiárida só é possível graças ao PIVAS, cujo fornecimento de água depende exclusivamente do complexo de barragens Coremas/Mãe d'água. Esse trabalho tem como objetivo caracterizar o consórcio, no ano de 2016, em seus aspectos ambientais, econômicos e sociais através de estudo de campo, fazendo uso de entrevistas e análises de água e solo. O fator limitante à produção do coco-da-baía e da banana foi o estresse hídrico decorrente da estiagem prolongada que assola a região desde 2012, afetando diretamente a produtividade e o perfil socioeconômico dos agricultores. Foi verificado que o racionamento de água no PIVAS afeta a produção, já que não supre adequadamente a demanda requerida pelas plantas cultivadas. A análise de água indicou sua não potabilidade, mas seu uso seguro para irrigação, de acordo com as diretrizes do Conama. A análise do solo indicou um empobrecimento generalizado do solo dos lotes estudados quando comparados ao solo da reserva legal.

Palavras-chave: Agricultura familiar, Policultura, Cultivo irrigado.

\section{Characterization of coconut-banana intercropping in the Irrigated Perimeter of the Sousa Floodplains, PB.}

\begin{abstract}
In the municipality of Sousa, Paraíba, family farmers from the Irrigated Perimeter of the Sousa Floodplains practice mixed intercropping with coconut trees and banana trees, aiming at a more constant and stable production over time. The representativeness of these high water-use plants in this semiarid locality is only possible thanks to the irrigated perimeter, whose water supply depends exclusively on the Coremas/Mãe d'água dam. This work aimed to characterize that mixed intercropping, in the year 2016, in its environmental, economic and social aspects, through a field study, using interviews and analyzes of water and soil. The most limiting factor for coconut and banana production was the water stress due to the drought that began in 2012, which directly affects the productivity of crops and socioeconomic profile of farmers. It was verified that the rationing of water in the perimeter affects the production, because it does not adequately supply the demand required by the cultivated plants. Water analysis indicated the nonpotability of water, but it was safe for irrigation according to Conama's guidelines. Soil analysis indicated a generalized impoverishment of the soil of the lots studied when compared to the soil of the legal reserve.
\end{abstract}

Keywords: Family farming, Mixed intercropping, Irrigated crop.

\section{INTRODUÇÃO}

O Perímetro Irrigado das Várzeas de Sousa (PIVAS) é uma iniciativa do Governo do Estado da Paraíba e do Ministério da Integração Nacional. A implantação do PIVAS teve início em 1999 com a desapropriação de 6.336 ha de terra dos municípios de Sousa e Aparecida através do Decreto n²0.834 de 29/12/1999. Do total dessa área, 992,53 ha estão distribuídos entre 178 pequenos irrigantes, dos quais 156 trabalham com fruticultura (BRASIL, 2012). A finalidade original do PIVAS foi irrigar uma área de 4.391 ha para produção de culturas que proporcionassem a produção de alimentos e geração de riqueza e emprego para a região.

$\mathrm{O}$ coqueiro e a bananeira estão dentre as lavouras permanentes relacionadas na produção nacional de frutíferas pelo Instituto Brasileiro de Geografia e Estatística (IBGE) e, em 2016, a banana foi considerada a segunda principal frutífera com relação a sua participação no valor da produção nacional, o coco-da-baía ficou na nona posição. Nesse mesmo ano, a região Nordeste foi responsável por $37,1 \%$ da produção de banana, sendo, a Paraíba, o quarto Estado de maior produção nessa região; da mesma forma, $81,8 \%$ da produção nacional de cocoda-baía teve proveniência do Nordeste, e a Paraíba manteve-se em sétimo lugar dentre os Estados da região (IBGE, 2016). Ambos são cultivos de alta demanda hídrica, sua representatividade, nessa região específica do semiárido, ocorre graças ao PIVAS, cujo fornecimento de água depende exclusivamente do complexo de barragens Coremas/Mãe d'água.

É possível observar a predominância desses plantios na paisagem local, em monocultivo ou em consórcios. Alguns agricultores familiares aproveitam o espaçamento entre os coqueiros para o

Recebido em 15/11/2018; Aceito para publicação em 21/03/2018

${ }^{1}$ Universidade Federal da Paraíba.

*E-mail: isawci@yahoo.com.br 
cultivo da bananeira e, uma das principais razões para os agricultores optarem por esse tipo de manejo, é o aumento da produção total do lote e a possibilidade de obter renda com mais de um produto agrícola. Abson et al. (2013) verificaram que a resiliência agrícola esteve positivamente correlacionada com a diversidade de uso do solo agrícola, a qual pode ter um papel importante no sentido de garantir maior retorno econômico em face de condições de mercado e ambientais incertos.

A consorciação é citada como capaz de promover uma produtividade mais estável e constante ao longo do tempo quando comparada ao monocultivo. A plantação de mais de uma espécie pode favorecer a conservação do solo, melhorando ou mantendo seus níveis de fertilidade e umidade (GLIESSMAN, 1985). Esse tipo de cultivo pode ser considerado uma condição para o alcance da sustentabilidade na agricultura, tanto por motivos ambientais, quanto por motivos econômicos e sociais. No local de estudo, o consórcio depende da água proveniente do PIVAS, no entanto, estudos sobre os perímetros irrigados no semiárido não têm mostrado níveis satisfatórios de sustentabilidade, apresentando problemas relacionados à baixa produtividade, dificuldades de comercialização e racionamento de água (AGUIAR NETTO et al., 2006). Nesse contexto, objetivou-se caracterizar o consórcio coqueiro-bananeira na agricultura familiar do PIVAS afim de saber se ele contribui com a produtividade local e se mantém o solo com características satisfatórias, ao mesmo tempo, também buscou-se relacionar o consórcio com a sua inserção em um perímetro irrigado no semiárido.

\section{MATERIAL E MÉTODOS}

O estudo foi realizado no município de Sousa no Estado da Paraíba, inserido em região semiárida, caracterizada pela irregularidade de chuvas e pelos baixos índices pluviométricos (BRASIL, 2012). A geologia local apresenta-se com predominância de rochas cristalinas e sedimentares, essas últimas nos domínios da bacia hidrográfica do Rio Piranhas, entre a região do Alto Piranhas e a sub-bacia do Rio do Peixe. O PIVAS ocupa uma área composta por solos do tipo Aluvial, representado pelos Neossolos Flúvicos com predominância de textura arenosa. Esse tipo de solo deixa os lotes vulneráveis às "cheias" do rio Piranhas, as quais são muito esporádicas, mas quando ocorrem, inundam as plantações (CORRÊA et al., 2003).

Foi realizado um estudo de campo, conduzido nos setores 6 e 7 do PIVAS, em lotes pertencentes a agricultores familiares que cultivam o coqueiro-anão em consórcio permanente com a bananeira cultivar Pacovan, ambos em fase produtiva (Figura 1).
A amostragem seguiu os critérios de saturação teórica, quando o incremento de novas observações não conduz a um aumento significativo de informações Thiry-Cherques, (2009). Dessa forma, no ano de 2016, foram estudadas nove famílias agricultoras que cultivavam coqueiro consorciado com bananeira, representadas numericamente de 1 a 9 para fins de preservação de suas identidades.

Todos os lotes foram caracterizados em seus aspectos sociais, econômicos e ambientais. A obtenção de dados junto aos agricultores familiares ocorreu por meio de entrevistas e observações diretas. Em cada lote foram coletadas 10 amostras aleatórias de solo que foram homogeneizadas para obtenção de uma amostra final para fins de análise química e de fertilidade no Laboratório de Análises de Solo e Água do IFPB/Sousa. Também foram coletadas amostras da água do reservatório do PIVAS para análise físico-química e bacteriológica no Laboratório de Águas do IFPB/João Pessoa.

\section{RESULTADOS E DISCUSSÃO}

Todos os lotes estudados eram de agricultura familiar, com área de 5 ha intensamente explorados para a implantação dos pomares de coqueiro e bananeira, com apenas uma pequena área reservada para a residência dos agricultores. Os lotes apresentavam muitas características em comum, desde o relevo e o clima, que não se modificavam a ponto de haver a formação de microclimas, à inserção no PIVAS, o qual distribuía a água igualitariamente para todos os pequenos irrigantes.

O início da produção dos coqueirais data de 2013, logo, a seca que teve início em 2012 atingiu o período em que os coqueiros estavam iniciando sua produção, nessa ocasião, as bananeiras já estavam implantadas e já produziam efetivamente. Quando a produção está plena, as condições de vida das famílias são muito satisfatórias, no entanto em situações de seca, como as observadas na ocasião dessa pesquisa, muitas famílias não conseguiam recursos financeiros suficientes para suprir sequer as suas necessidades mais básicas.

Os lotes do perímetro, em sua totalidade, apresentavam estrutura para irrigação através de técnica de microaspersão, bem como estrutura para drenagem de água. Cada lote possuía hidrômetro e os agricultores pagavam tarifas de água referentes à amortização dos investimentos realizados para implantação do perímetro (tarifa K1) e referente aos valores gastos com operação e manutenção do sistema de irrigação (tarifa K2). Com relação ao esgoto sanitário, todos os lotes visitados possuíam fossa séptica a qual era destinado. A energia elétrica de todos os lotes era fornecida pela concessionária local. 


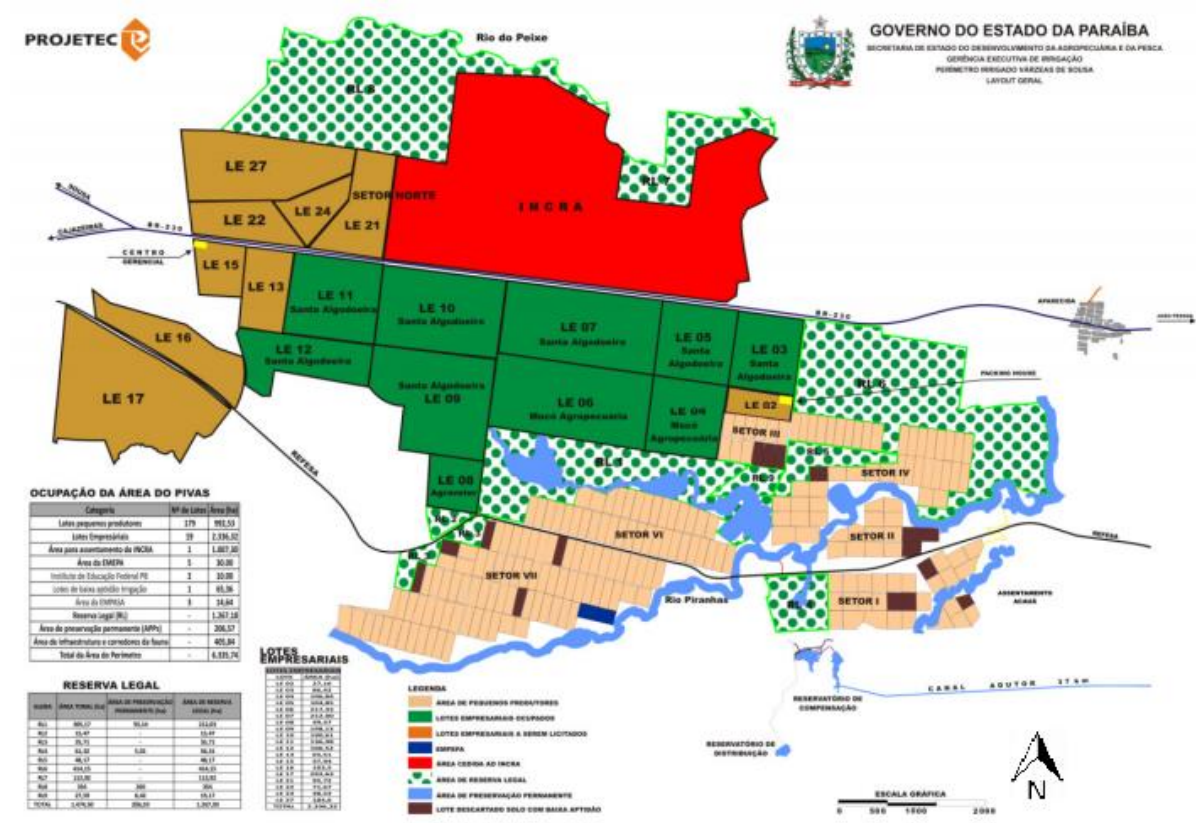

Figura 1. Área total ocupada pelo PIVAS. Fonte: DPIVAS (2010)

\section{Consórcio}

O coqueiral foi implantado com espaçamento de $7 \times 7$ metros e, em seguida, as bananeiras foram plantadas entre os coqueiros. $\mathrm{O}$ coqueiro-anão precisa de 3 a 4 anos para iniciar a produção, a bananeira inicia sua produção entre 12 e 14 meses após o plantio. Enquanto a bananeira produzia e garantia renda para a família agricultora, o coqueiro completava seu desenvolvimento.

Os tratos culturais realizados para a manutenção do coqueiral se referiam à coroação, que é a limpeza da área ao redor da planta, geralmente num raio de $2 \mathrm{~m}$ a partir do estipe, e à roçagem nas entrelinhas, ambas com o mesmo objetivo de impedir a competição com ervas daninhas e evitar o uso de herbicidas (BENASSI et al., 2007). Para as bananeiras, a manutenção era feita através do desbaste, que consiste na eliminação dos rebentos; desfolha, eliminação das folhas mortas, secas ou injuriadas; escoramento da planta para evitar seu tombamento devido ao peso do cacho; e corte do pseudocaule após a colheita (LICHTEMBERG e LICHTEMBERG, 2011). A adubação foi feita anualmente e nem sempre foi precedida de análise de solo. Eventualmente foi necessário o uso de agrotóxicos para o combate de pragas no coqueiral, frequentes na região. Apesar do aparente conhecimento dos agricultores, foi percebido que havia muita insegurança sobre a adubação e o combate à pragas.

A colheita do coco era realizada, em média, a cada 40 dias, naquela ocasião, muitos agricultores contratavam mão de obra extra. De um modo geral, os cuidados com o coqueiral não foram considerados muito desgastantes para os agricultores, os quais eram realizados pela própria família, exceto a colheita, pois em muitos dos casos ela era totalmente entregue a atravessadores, que tinham pressa para ter acesso à produção. A colheita da banana ocorria em média a cada 7 meses e a mão de obra era da própria família.

$\mathrm{O}$ alto requerimento hídrico dessas plantas foi o fator mais preocupante para os agricultores que, ao longo do tempo, observaram diminuição da vazão de água para os lotes e a consequente diminuição da produção. Com menos água, a produção foi visivelmente prejudicada e muitos agricultores dependiam exclusivamente desses cultivos (FERREIRA NETO et al., 2007; COELHO et al., 2013).

As famílias estudadas possuíam conhecimentos técnicos acerca do manejo de produção dessas frutíferas, essas informações foram acumuladas ao longo do tempo de trabalho na agricultura, muitas vezes passando de geração a geração, bem como através dos cursos de capacitação oferecidos pelo DPIVAS (Distrito de Irrigação do PIVAS - órgão administrativo) desde sua instalação. Os agricultores também se ajudavam mutuamente, tanto na troca de informações, quanto na troca de serviços nas plantações.

\section{Condições do solo}

Com relação ao tipo de adubação utilizado pelos agricultores, $66,6 \%$ faziam o uso de fertilizantes químicos; 22,2\% usavam fertilizantes químicos e orgânicos; e apenas $11,1 \%$ usavam unicamente fertilizantes orgânicos em suas plantações. Quanto à presença de ervas daninhas no pomar, apenas $11,1 \%$ não apresentavam infestação, $55,5 \%$ dos demais 
lotes usavam herbicidas para controle e 33\% faziam o controle das ervas através de roçagem mecânica. Todos os agricultores aproveitavam os restos culturais do coqueiral como cobertura morta, a qual traz grande benefício ao solo, uma vez que quanto maior a cobertura da superfície do solo, maior é a proteção da sua estrutura contra perturbações naturais e antropogênicas, ajudando, por exemplo, no controle da erosão hídrica, mantendo as taxas de infiltração de água favoráveis, mantendo resíduos orgânicos na superfície, reduzindo a evaporação e a temperatura do solo (COSTA et al., 2013; MIRANDA et al., 2007).

Dentre os parâmetros verificados na análise química e de fertilidade do solo, Gomes e Filizola (2006) determinam como mais importantes: $\mathrm{pH}$; $\mathrm{P}$, $\mathrm{K}, \mathrm{Ca}$ e Mg (Fósforo, Potássio, Cálcio e Magnésio, respectivamente); e a CTC (Capacidade de Troca de Catiônica).

$\mathrm{O}$ valor do $\mathrm{pH}$ relaciona-se com a disponibilidade de nutrientes para a planta, facilitando ou dificultando sua absorção através das raízes. De uma maneira geral, o nitrogênio $(\mathrm{N})$ é mais facilmente absorvido pela planta em solo com $\mathrm{pH}$ acima de 5,5 sendo que a disponibilidade máxima desse nutriente no solo verifica-se na faixa de $\mathrm{pH}$ entre 6 e 6,5, para depois diminuir. $\mathrm{O}$ fósforo $\left(\mathrm{P}_{2} \mathrm{O}_{5}\right)$ tem melhor disponibilidade para as plantas em $\mathrm{pH} 6$ a 6,5. O potássio $\left(\mathrm{K}_{2} \mathrm{O}\right)$ é melhor aproveitado pelas plantas em solos com $\mathrm{pH}$ maior que 5,5 (BRAGA, 2012). Gomes e Filizola (2006), afirmam que os solos com condições ideais para cultivo devem apresentar $\mathrm{pH}$ no intervalo entre 6,0 e 6,5 podendo ser estendido para o intervalo entre 5,5 e 6,8. Os resultados da análise laboratorial mostraram que os solos dos lotes estudados apresentavam $\mathrm{pH}$ no intervalo entre 7,5 e 8,5, portanto, esse componente apresentou-se numa condição não favorável ao cultivo do coqueiro e da bananeira, no tocante à facilitação da nutrição dessas plantas.

Com relação aos macronutrientes $\mathrm{P}, \mathrm{K}, \mathrm{Ca}$ e $\mathrm{Mg}$, não existem trabalhos feitos especificamente para os solos de Sousa, onde está inserido o PIVAS, levando em consideração a demanda das plantações por eles. Teixeira et al. (2005) observaram que a exigência de fósforo pelo coqueiro é relativamente pequena e também constataram que $19 \mathrm{mg} \mathrm{dm}^{-3}$ de fósforo disponível no solo foram suficientes para manter a sua concentração foliar em níveis considerados adequados. O coqueiro é muito exigente em potássio (K) e, ao mesmo tempo, muito eficiente na acumulação desse nutriente (TEIXEIRA et al., 2005). Sobral et al. (2009) recomendam que o teor de cálcio (Ca) disponível no solo para o coqueiro seja superior à $2,0 \mathrm{cmol}_{\mathrm{c}} \mathrm{dm}^{-3}$ e que a concentração de magnésio (Mg) no solo recomendada para a nutrição adequada do coqueiro deve ser superior a $2,0 \mathrm{cmolc} \mathrm{dm}^{-3}$. A bananeira é muito exigente quanto a absorção de nutrientes, sendo o $\mathrm{K}$ e o $\mathrm{N}$ os mais solicitados, seguidos pelo $\mathrm{Mg}$ e pelo $\mathrm{Ca}$, o requerimento de $\mathrm{P}$ não é considerado alto, de forma que teores de $30 \mathrm{mg} \mathrm{dm}^{-3}$ de $\mathrm{P}$ no solo, dispensam adubação (BARBOSA et al., 2013).

A CTC está relacionada com a capacidade do solo de reter cátions trocáveis, evitando perda de nutrientes por lixiviação, quanto maior a CTC, também é maior a graduação da capacidade de liberação de vários nutrientes, favorecendo a manutenção da fertilidade do solo por um período mais prolongado, reduzindo ou evitando a ocorrência de efeitos tóxicos da aplicação de fertilizantes (RONQUIM, 2010, BRAGA, 2012). Na análise de solo realizada nesse trabalho foi medida a CTC total, a qual considera todos os cátions permutáveis do solo $\left(\mathrm{Ca}^{2+}+\mathrm{Mg}^{2+}+\mathrm{K}^{+}+\mathrm{H}^{+}+\mathrm{Al}^{3+}\right)$.

Para nortear a interpretação da análise do solo dos lotes, foram considerados dados de uma análise do solo da área de reserva legal (RL) do PIVAS feita em 06/08/2013 e disponibilizada pelo Laboratório de Análise de Solo e Água do IFPB campus Sousa. Nessa análise os valores medidos foram: $\mathrm{pH}=6,3$; $\mathrm{P}=99 \mathrm{mg} \mathrm{dm}^{-3} ; \mathrm{K}=0,35 \mathrm{cmol}_{\mathrm{c}} \mathrm{dm}^{-3} ; \mathrm{Ca}=8,6 \mathrm{cmol}_{\mathrm{c}}$ $\mathrm{dm}^{-3} ; \mathrm{Mg}=2,9 \mathrm{cmol}_{\mathrm{c}} \mathrm{dm}^{-3} ;$ e CTC $=14,1 \mathrm{cmol}_{\mathrm{c}} \mathrm{dm}^{-3}$. Em comparação aos valores obtidos nas análises de solo dos lotes, verificou-se uma grande modificação no $\mathrm{pH}$, que era ácido na RL e alcalino em todos eles; o P encontrava-se em menor concentração em 88,9\% os lotes, quando comparado à concentração da RL; o $\mathrm{K}$ encontrava-se em menor concentração em todos os lotes, quando comparado a RL; o Ca estava em concentrações inferiores a da RL em $66,6 \%$ dos lotes analisados; em $66.6 \%$ dos lotes, o $\mathrm{Mg}$ foi encontrado em menor concentração do que a verificada na RL; a CTC de 88,9\% dos lotes encontrava-se abaixo da CTC da RL. Através dessa comparação, foi inferido o empobrecimento do solo da maioria dos lotes com relação aos parâmetros supracitados (Tabela 1). 


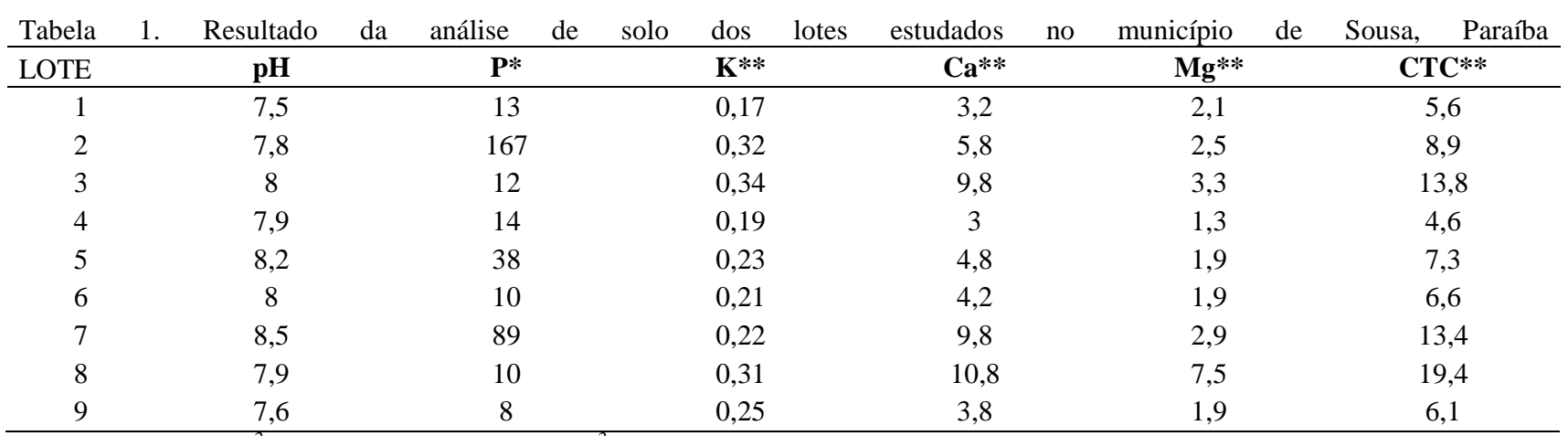

*medido em mg dm${ }^{-3} \quad * *$ Medidos em $\mathrm{cmol}_{\mathrm{c}} \mathrm{dm}^{-3}$

Fonte: Elaboração própria (2017)

Os resíduos domésticos das famílias dos lotes estudados eram depositados, em sua maioria $(66,6 \%)$ em terreno destinado para esse fim, para que, posteriormente, pudesse ser coletado pelo DPIVAS. As demais famílias faziam a queima de seu lixo no próprio lote. Com relação ao descarte das embalagens de agrotóxicos e fertilizantes químicos utilizadas no manejo das plantações, a lei $n^{\circ} 9.974$ de 6 de junho de 2000 dispõe que os usuários de agrotóxicos deverão devolver as embalagens vazias dos produtos aos estabelecimentos comerciais onde foram adquiridos ou em postos de recolhimento autorizados por órgão competente, levando em consideração as instruções contidas na bula e o prazo de 1 ano a contar da data de compra (BRASIL, 2000). No tocante ao descarte das embalagens de fertilizantes, não há lei que o regulamente, mas sabe-se que o risco do descarte inadequado, bem como o uso inadequado de fertilizantes, está relacionado à salinização do solo (SOBRAL et al., 2009). A totalidade dos agricultores estudados entregava essas embalagens ao DPIVAS, o qual as devolvia aos estabelecimentos comerciais onde foram adquiridas.

\section{Condição hídrica}

A análise laboratorial procurou obter dados sobre a qualidade da água que era distribuída em todo o PIVAS, a análise bacteriológica acusou forte contaminação por coliformes totais e coliformes termotolerantes, acusando sua não potabilidade e, portanto, sua condição de imprópria para consumo humano. Contudo, segundo a Resolução Conama 357 de 17 de março de 2005 (BRASIL, 2005), essa água é passível de ser utilizada na agricultura para fins de irrigação. Quanto à análise físico-química, a mesma corroborou a análise bacteriológica no tocante a não potabilidade da água. Os requisitos mais importantes para a qualidade da água de irrigação se mantiveram dentro do considerado "normal", a exemplo da baixa salinidade, indicando a água do PIVAS como boa para a grande maioria das plantas e com pouca probabilidade de comprometer o solo. $\mathrm{O}$ pH, medido em 7,83, também foi considerado viável para as plantações e incapaz de causar problemas de deterioração do equipamento de irrigação (SILVA et al., 2011).

Por causa da não potabilidade da água no PIVAS, havia grande preocupação acerca da origem da água para consumo humano, ainda assim, 22,25\% famílias utilizavam a água do PIVAS para seu consumo, fazendo tratamento através de filtração e fervura, a fim de evitar contaminação; $55,5 \%$ das famílias utilizavam a água das cisternas ou cacimbões de suas propriedades; enquanto $22,25 \%$ das famílias fizeram opção por utilizar água mineral ou água potável comercializada informalmente nas redondezas dos lotes.

Devido ao clima da região, muitos agricultores buscavam alternativas para suprir suas demandas por água através da construção de cisternas e cacimbões em seus lotes, inclusive muitos deles não obtiveram sucesso nessa empreitada, dada a indisponibilidade de água no subsolo de suas propriedades. Assim, 66.6\% dos agricultores possuíam fontes de água provenientes de cisternas ou cacimbões em seus lotes para auxiliar na irrigação, deixando-os mais independentes da água no PIVAS.

Com relação à irrigação dos pomares, $88,8 \%$ dos agricultores ofereciam menos água do que o requerido pelas plantas, que, em resposta a isso, não apresentavam bons índices de produtividade, uma vez que ambas são muito exigentes quanto a esse recurso. A frequência de irrigação dos lotes dependia exclusivamente da liberação de água pelo DPIVAS, mas apesar de todas as limitações, 88,8\% dos agricultores permaneciam irrigando suas plantações de segunda à sexta-feira ou de segunda à domingo, dependendo da oferta do perímetro. Deve ser considerado que a duração do fornecimento de água era de duas horas, em média, e que a vazão estava inferior à projetada.

É amplamente conhecido que a agricultura é uma grande demandadora de água, com estimações 
de ser responsável pelo uso| de $70 \%$ de toda a água consumida no mundo. A agricultura irrigada é de extrema importância para a produção agrícola, mas depende da disponibilidade ou alocação específica de recursos hídricos que, em regiões semiáridas, sofrem forte sazonalidade e risco de secas. Embora a irrigação do PIVAS seja considerada racionalizadora do uso da água na agricultura, o problema encontra-se nas fontes de água que se destinam ao perímetro, que tiveram forte déficit nos últimos anos, pondo em risco todas as plantações (LUNARDI, RABAIOLLI, 2003; SILVA et al., 2016; SILVA et al., 2017). Em julho de 2017, o açude Coremas estava com menos de $10 \%$ da capacidade e Mãe d'água com 5,6\% (DNOCS, 2017). A situação delicada de escassez de água no PIVAS não lhe era exclusiva, nesse mesmo período, 8 perímetros irrigados do Ceará (Ayres de Souza, Curu-Paraipaba, CuruPentecoste, Ema, Forquilha, Morada Nova, Quixabinha, Várzea do Boi), Estado que concentra $40 \%$ dos perímetros irrigados do Nordeste, encontravam-se inoperantes por falta de água (BEZERRA, 2017). Em agosto de 2017, 196 dos 223 municípios da Paraíba estavam em situação de emergência por causa da seca (MOURA, 2017).

$O$ trabalho no campo encontrava-se mais centralizado na figura do homem, com jornada de trabalho de cerca de 8 horas diárias, Barth et al. (2016) comentam que raramente os trabalhadores rurais gozam de períodos de férias, não havendo períodos mais longos de descanso durante o ano. $62,5 \%$ dos filhos das famílias estudadas ajudavam nas atividades realizadas nas plantações, mas, nessa mesma porcentagem, $62,5 \%$ dos pais responderam que seus filhos não queriam permanecer no campo, pretendendo trabalhar em atividades não relacionadas à agricultura. $\mathrm{O}$ desejo de continuidade do trabalho agrícola nas futuras gerações da família, foi questionado aos agricultores. Metade deles respondeu que não tinha interesse que os filhos dessem continuidade às suas atividades no campo, preferindo que eles pudessem estudar a fim de alcançar êxito em outras profissões. $\mathrm{O}$ desprezo dedicado à agricultura está associado às oportunidades de emprego e estudo em outras localidades, com possibilidade de rendas maiores (SARTRE, 2009).

A participação dos agricultores em associações e sindicatos lhes dá voz perante a sociedade, além de lhes incentivar a aliar forças para a defesa dos seus interesses e direitos (SENAR, 2011). 66,7\% dos agricultores são filiados ao sindicato e 55,6\% participavam de alguma associação relacionada ao PIVAS.

Segundo Minayo (2000, p.14), "qualidade de vida em saúde coloca sua centralidade na capacidade de viver sem doenças ou de superar as dificuldades dos estados ou condições de morbidade". Com essa intenção, foi perguntado aos agricultores qual o seu "estado de saúde" a fim de verificar a percepção de saúde do agricultor e sua família com relação à frequência em que adoecem no período de 1 ano, a totalidade afirmou que adoece raramente ao longo do ano.

Quanto ao nível escolar dos agricultores, 55,5\% deles tinham ensino fundamental incompleto; apenas $11,1 \%$ tinham ensino médio completo, que foi o nível de escolaridade mais alto encontrado na pesquisa. Em 55,5\% das famílias estudadas, os filhos tinham maior grau de escolaridade que os pais, os quais valorizavam o estudo dos filhos. Também foi avaliada a facilidade de acesso que a família agricultora tem à escola, posto de saúde, transporte público, médicos, visita de agentes de saúde nas residências, dentistas e hospitais. A Tabela 2 mostra as respostas dos agricultores a esse questionamento, que foi respondido como acesso "ruim", "razoável" e "bom".

Tabela 2. Avaliação das famílias quanto aos serviços públicos prestados na região.

\begin{tabular}{|c|c|c|c|c|c|c|c|c|c|c|c|c|c|c|c|c|c|c|c|c|c|}
\hline \multirow[b]{2}{*}{ Lote } & \multicolumn{3}{|c|}{ Escola } & \multicolumn{3}{|c|}{ Posto } & \multicolumn{3}{|c|}{ Transporte } & \multicolumn{3}{|c|}{ Médicos } & \multicolumn{3}{|c|}{ Agentes } & \multicolumn{3}{|c|}{ Dentistas } & \multicolumn{3}{|c|}{ Hospital } \\
\hline & $\mathrm{Ru}$ & $\mathrm{Ra}$ & B & $\mathrm{Ru}$ & $\mathrm{Ra}$ & B & $\mathrm{Ru}$ & $\mathrm{Ra}$ & B & $\mathrm{Ru}$ & $\mathrm{Ra}$ & B & $\mathrm{Ru}$ & $\mathrm{Ra}$ & $\mathrm{B}$ & $\mathrm{Ru}$ & $\mathrm{Ra}$ & B & $\mathrm{Ru}$ & $\mathrm{Ra}$ & B \\
\hline 1 & & & $\mathrm{x}$ & $\mathrm{x}$ & & & $\mathrm{x}$ & & & $\mathrm{x}$ & & & & $\mathrm{x}$ & & $\mathrm{x}$ & & & $\mathrm{x}$ & & \\
\hline 2 & & & $\mathrm{X}$ & & & $\mathrm{X}$ & & $\mathrm{X}$ & & $\mathrm{X}$ & & & & & $\mathrm{X}$ & & $\mathrm{X}$ & & & & $\mathrm{X}$ \\
\hline 3 & & & $\mathrm{X}$ & & $\mathrm{X}$ & & $\mathrm{X}$ & & & & $\mathrm{X}$ & & & & $\mathrm{X}$ & & & $\mathrm{X}$ & & & $\mathrm{X}$ \\
\hline 4 & & $\mathrm{X}$ & & & & $\mathrm{X}$ & $\mathrm{x}$ & & & & & $\mathrm{X}$ & & & $\mathrm{X}$ & & $\mathrm{X}$ & & & & $\mathrm{X}$ \\
\hline 5 & $\mathrm{x}$ & & & $\mathrm{X}$ & & & $\mathrm{x}$ & & & $\mathrm{X}$ & & & & $\mathrm{X}$ & & $\mathrm{X}$ & & & $\mathrm{X}$ & & \\
\hline 6 & & & $\mathrm{X}$ & & $\mathrm{X}$ & & $\mathrm{x}$ & & & $\mathrm{X}$ & & & $\mathrm{x}$ & & & $\mathrm{x}$ & & & & & $\mathrm{X}$ \\
\hline 7 & & & $\mathrm{X}$ & $\mathrm{x}$ & & & & $\mathrm{x}$ & & $\mathrm{X}$ & & & & $\mathrm{x}$ & & & & $\mathrm{x}$ & & & $\mathrm{X}$ \\
\hline 8 & & & $\mathrm{X}$ & & $\mathrm{X}$ & & $\mathrm{x}$ & & & & $\mathrm{X}$ & & & $\mathrm{X}$ & & & $\mathrm{X}$ & & & & $\mathrm{X}$ \\
\hline 9 & & $\mathrm{X}$ & & & & $\mathrm{X}$ & $\mathrm{X}$ & & & & & $\mathrm{X}$ & & & $\mathrm{X}$ & & $\mathrm{X}$ & & & & $\mathrm{X}$ \\
\hline
\end{tabular}

Legenda: $\mathrm{Ru}=$ Ruim; $\mathrm{B}=$ Bom e Ra = Razoável. 
$\mathrm{O}$ acesso à escola, foi considerado bom por $66,6 \%$ dos agricultores; o mesmo não ocorreu com acesso ao transporte público, que foi avaliado como ruim por $77,7 \%$ dos entrevistados. $\mathrm{O}$ acesso ao posto de saúde foi considerado bom por $33,3 \%$ dos entrevistados; o acesso aos serviços médicos foi considerado ruim por 55,5\%; e o acesso aos agentes de saúde considerado razoável por $44,4 \%$ dos entrevistados. $\mathrm{O}$ acesso aos dentistas foi analisado por $44,4 \%$ dos entrevistados como razoável; enquanto $77,7 \%$ consideraram bom o acesso aos hospitais.

A comercialização da produção era feita, em $88,8 \%$ dos casos, por intermédio de atravessadores, que, por sua vez, determinavam os preços das frutas e compravam a totalidade da produção, num processo que retira uma parcela da renda do agricultor (NASCIMENTO et al., 2016). Algumas famílias possuíam renda não proveniente da agricultura, mas $44,5 \%$ dessas dependiam exclusivamente da renda provinda dela. $88,8 \%$ dos lotes faziam uso de créditos agrícolas e isso era visto de forma positiva, pelo seu apoio ao desenvolvimento das atividades da agricultura familiar. O consórcio coqueiro-bananeira viabiliza renda ao agricultor na fase de implantação do coqueiral, quando a banana ocupa o solo e inicia sua produção sem afetar o coqueiral em termos de espaço e de desenvolvimento.

Com relação à produtividade do coqueiral no PIVAS, a cada 40 dias ocorria colheita de frutos para comercialização. Segundo Michereff Filho (2008), o coqueiro-anão pode produzir entre $150 \mathrm{e}$ 250 frutos/planta/ano na região Nordeste; em média, em 1 ha de terra há cerca de 200 plantas. Considerando que um coqueiro produza 150 frutos em 365 dias, ao fim de 1 ano, o coqueiral produz, minimamente, 30.000 frutos/ha. Considerando a produção máxima do coqueiro, ele fornece 200 frutos em 365 dias, assim, ao fim de 1 ano, a produção máxima seria de 50.000 frutos/ha. Na ocasião dessa pesquisa, todos os lotes produziam muito abaixo do esperado, numa média de 3.363 frutos/ha ao longo do ano, reflexo da grave crise hídrica da região. Quanto ao bananal, o rendimento (tonelada/ha) dos lotes foi de aproximadamente 1,2 tonelada/ha, o rendimento da bananeira em áreas de grande produção alcança cerca de 25 toneladas/ha (NOMURA et al., 2013). A produtividade aquém do esperado está relacionada, principalmente, ao baixo suprimento de água decorrente da seca que assolava a região no período dessa pesquisa. Coqueiros e bananeiras são culturas de grande demanda hídrica. A bananeira é muito susceptível à seca, o déficit hídrico influencia negativamente nas características do fruto (massa, comprimento, diâmetro, relação polpa/casca), e na sua resistência ao despencamento
(CASTRICINI et al., 2012). Um forte fator limitante para a produção do coqueiro-anão é o estresse hídrico, o qual manifesta-se através do aborto de inflorescências e redução do número e tamanho dos frutos (LUNARDI, RABAIOLLI, 2003, SILVA et al., 2016, SILVA et al., 2017). Temperaturas mais elevadas aumentam a evapotranspiração, demandando mais água para irrigação, situação agravada em períodos de baixas precipitações (GONDIM et al., 2011).

Mesmo sendo considerado um manejo mais adequado, o consórcio não desempenha seu papel de mantenedor de estabilidade da produção, se não tem condições de funcionar adequadamente devido ao racionamento e a falta de água. Segundo Paz et al. (2000), é necessário que haja controle e administração adequados dos recursos hídricos, caso contrário, não será possível uma agricultura sustentável.

\section{CONCLUSÕES}

1. Racionamento de água no perímetro irrigado afeta a produção, já que não supre adequadamente a demanda requerida pelas plantas cultivadas, independente do seu tipo de manejo.

2. O solo encontrava-se empobrecido na maioria dos lotes estudados, quando comparados ao solo da reserva legal.

\section{REFERÊNCIAS}

ABSON, D.J., FRASER, E.D.G., BENTON, T.G. Landscape diversity and resilience of agricultural returns: a portfolio analysis of land-use patterns and economic returns from lowland agriculture. Agriculture \& Food Security, London, v.2., n.2, p.101-112, 2013.

AGUIAR NETTO, A.O., MACHADO, R., VARGAS, M.A.M. Sustentabilidade do perímetro irrigado Jabiberi. Revista Ra' ega, Curitiba, n.12, p.153-159, 2006.

BARBOSA, F.E.L., LACERDA, C.F., FEITOSA, H.O., SOARES, I., ANDRADE FILHO, F.L., AMORIM, A.V. Crescimento, nutrição e produção da bananeira associados a plantas de cobertura e lâminas de irrigação. Revista Brasileira de Engenharia Agrícola e Ambiental, Campina Grande, v.17, n.12, p.1271-1277, 2013.

BARTH, M. RENNER, J.S.; NUNES, M.F.; SANFELICE, G.R. Características do trabalho na agricultura familiar e sua influência na emigração dos jovens. Iluminuras, Porto Alegre, v.17, n.41, p.256-276, 2016.

BENASSI, A.C., RUGGIERO, C., MARTINS, A.B.G., SILVA, J.A.A. Caracterização biométrica de frutos de coqueiro, Cocos nucifera L. variedade anã-verde, em diferentes estádios de desenvolvimento. Revista 
Brasileira de Fruticultura, Jaboticabal, v.29, n.2, p.302307, 2007.

BEZERRA, R. Em meio a seca, DNOCS tenta se reerguer e manter funções. 2017. Disponível em: http://diariodonordeste.verdesmares.com.br/cadernos/cida de/em-meio-a-seca-dnocs-tenta-se-reerguer-e-manterfuncoes-1.1806744. Acesso em: 29 de ago. 2017.

BRAGA, G.N.M. O pH do Solo e a Disponibilidade de Nutrientes. 2012. Disponível em: < http://agronomiacomgismonti.blogspot.com.br/2012/01/oph-do-solo-e-disponibilidade-de.html >. Acesso em: $31 \mathrm{de}$ mai. 2017.

BRASIL. Congresso Nacional. Lei $\mathrm{n}^{\circ} 9.974$ de 6 de junho de 2000. Altera a Lei no 7.802, de 11 de julho de 1989, que dispõe sobre a pesquisa, a experimentação, a produção, a embalagem e rotulagem, o transporte, o armazenamento, a comercialização, a propaganda comercial, a utilização, a importação, a exportação, o destino final dos resíduos e embalagens, o registro, a classificação, o controle, a inspeção e a fiscalização de agrotóxicos, seus componentes e afins, e dá outras providências. Diário Oficial da União, Brasília, DF, 2000. Disponível em: <http://www.planalto.gov.br/ccivil_03/leis/L9974.htm\#art 5>. Acesso em: 15 de jan. 2017.

BRASIL. Ministério do Meio Ambiente. Resolução n⿳357 de 17 de março de 2005. Dispõe sobre a classificação dos corpos de água e diretrizes ambientais para o seu enquadramento, bem como estabelece as condições e padrões de lançamento de efluentes, e dá outras providências. 2005. Disponível em: < http://www.mma.gov.br/port/conama/res/res05/res35705. pdf $>$. Acesso em: 15 de mai. 2017.

BRASIL. Ministério da Integração Nacional (MIN). Implantação do Perímetro de Irrigação Várzeas de Sousa. 2012. Disponível em: <http://www.integracao.gov.br/projeto-varzeas-de-sousapb>. Acesso em: 20 de jul. 2017.

CASTRICINI, A., COELHO, E.F., RODRIGUES, M.G.V., COUTINHO, R.C. Caracterização pós-colheita de frutos de bananeira 'BRS Platina' de primeiro ciclo, sob regulação do déficit de irrigação. Revista Brasileira de Fruticultura, Jaboticabal, p.1013-1021, v.34, n.4, 2012.

COELHO, E.F., OLIVEIRA, R.C., PAMPONET, A.J.M. Necessidades hídricas de bananeira tipo Terra em condições de tabuleiros costeiros. Pesquisa Agropecuária Brasileira, Brasília, v.48, n.9, p.12601268, 2013.

CORRÊA M.M.C., KER J.C., MENDONÇA E.S., RUIZ H.A., BASTOS, R.S. Atributos Físicos, químicos e mineralógicos de solos da região das Várzeas de Sousa (PB). Revista Brasileira de Ciências do Solo, Viçosa, v.27, n.2, p.311-324, 2003.
COSTA, E.M., SILVA, H.F., RIBEIRO, P.R.A. Matéria orgânica do solo e o seu papel na manutenção e produtividade dos sistemas agrícolas. Enciclopédia Biosfera, Goiânia ,v.9, n.17, p.61-74, 2013.

DNOCS inicia recuperação e modernização de Curema/Mãe d’Água. 2017. Disponível em: < http://www2.dnocs.gov.br/gab-cs/3668-dnocs-iniciarecuperacao-e-modernizacao-do-curema-mae-agua>. Acesso em: 29 de ago. 2017.

FERREIRA NETO, M., GHEYI, H.R., FERNANDES, P.D., HOLANDA, J.S., BLANCO, F.F. Emissão foliar, relações iônicas e produção do coqueiro irrigado com água salina. Ciência Rural, Santa Maria, v.37, n.6, p.1675-1681, 2007.

GLIESSMAN, S. R. Multiple cropping systems: A basis for developing an alternative agriculture. In: Innovative biological technologies for lesser developed countriesworkshop proceedings. Washington, 1985, p.69-83.

GOMES, M.A.F., FILIZOLA H.F. Indicadores físicos e químicos de solo de interesse agrícola. Jaguariúna: Embrapa Meio Ambiente, 2006, 234p.

GONDIM, R.S., CASTRO, M.A.H., TEIXEIRA, A.S., EVANGELISTA, S.R.M. Impactos das mudanças climaticas na demanda de irrigação da bananeira na Bacia do Jaguaribe. Revista Brasileira de Engenharia Agrícola e Ambiental, Campina Grande, v.15, n..6, p.594-600, 2011.

INSTITUTO BRASILEIRO DE GEOGRAFIA E ESTATÍSTICA (IBGE). Levantamento sistemático da produção agrícola. Rio de Janeiro: Instituto Brasileiro de Geografia e Estatística, 2016, 118p.

LICHTEMBERG, L.A., LICHTEMBERG, P.S.F. Avanços na bananicultura brasileira. Revista Brasileira de Fruticultura, Jaboticabal, volume especial, p.29-36, 2011.

LUNARDI J., RABAIOLLI, J.A. Valorização e preservação dos recursos hídricos na busca pelo desenvolvimento rural sustentável. Okara: Geografia em debate, João Pessoa, v.7, n.1, p.44-62, 2013.

MICHEREFF FILHO, M., SOBRAL, L.F., FERREIRA, J.M.S., RODRIGUES, A.R.S., MICHEREFF, M.F.F. Adubação química, ataque do ácaro Aceria guerreronis e produtividade do coqueiro 'Anão-Verde'. Pesquisa Agropecuária Brasileira, Brasília, v.43, n.3, p.303-308, 2008.

MINAYO, M.C. Qualidade de vida e saúde: um debate necessário. Ciência \& Saúde coletiva, Rio de Janeiro, v.5, n.1, p.7-18, 2000.

MIRANDA, F., SOUSA, C., CRISÓSTOMO, L. Use of coconut dusk as mulch on green dwarf coconut. Revista Ciência Agronômica, Fortaleza, v.38, n.1, p.41-45, 2007. 
MOURA, R. País tem um quarto das cidades em emergência causada por seca ou chuva. 2017. Disponível em: http://www1.folha.uol.com.br/cotidiano/2017/08/1913593 -pais-tem-23-das-cidades-em-situacao-de-emergenciapor-inundacoes-e-secas.shtml. Acesso em: 29 de ago. 2017.

NASCIMENTO, J.S., BEZERRA, G.J., SCHLINDWEIN, M.M., PADOVAN, M.P. Produção agropecuária, agregação de valor e comercialização pela agricultura familiar no Estado do Mato Grosso do Sul. Redes, Santa Cruz do Sul, v. 21, n.3, p.320 - 334, 2016.

NOMURA, E.S., DAMATTO JUNIOR, E.R., FUZITANI, E.J., AMORIM, E.P., SILVA, S.O. Avaliação agronômica de genótipos de bananeiras em condições subtropicais, Vale do Ribeira, São Paulo Brasil. Revista Brasileira de Fruticultura, Jaboticabal, v.35, n.1, p.112-122, 2013.

PAZ, V.P.S.; TEODORO, R.E.F.; MENDONÇA, FC. Recursos hídricos, agricultura irrigada e Meio ambiente. Revista Brasileira de Engenharia Agrícola Ambiental, Campina Grande, v.4, n.3, p.465-473, 2000.

RONQUIM, R.C. Conceitos de fertilidade do solo e manejo adequado para as regiões tropicais. Campinas: Embrapa Monitoramento por satélite, 2010, 30p.

SARTRE, X.A. Entre condição de agricultor e profissão: reproduções e construções sociais de jovens agricultores da fronteira agrícola amazônica. Anuário Americanista Europeu, Helsinki, n.6-7, p.161-184, 2009.

SENAR. Associações rurais: práticas associativas, características e formalização. Brasília: Serviço Nacional de Aprendizagem Rural, 2011, 56p.
SILVA, I.N., FONTES, L.O., TAVELLA, L.B., OLIVEIRA, J.B., OLIVEIRA, A.C. Qualidade de água na irrigação. Revista de Agropecuária Científica no Semiárido, Patos, v.7, n.3, p.1-15, 2011.

SILVA, A.R.A., BEZERRA, F.M.L., LACERDA, C.F., ARAÚJO, M.E.B., LIMA, R.M.M., SOUZA, C.H.C. Establishment of young "dwarf g reen" coconut plants in soil affected by salts and under water deficit. Revista Brasileira de Fruticultura, Jaboticabal, v.38, p.1-12, n.3, 2016.

SILVA, A.R.A., BEZERRA, F.M.L., LACERDA, C.F., SOUZA, C.H.C, BEZERRA, A.M. Respostas fisiológicas de plantas de coqueiro anão sob deficiência hídrica, em solos afetados por sais. Revista Caatinga, Mossoró, v.30, n.2, p.447-457, 2017.

SOBRAL, L.F., FREITAS, J.A.D., HOLANDA, J.S., FONTES, H.R., CUENCA, M.A.G., RESENDE, R.S. Coqueiro anão verde. In: CRISÓSTOMO, L.A., NAUMOV, A. Fruteiras tropicais do Brasil, Fortaleza, CE. 2009. p.89-103

TEIXEIRA, L.A.J., BATAGLIA, O.C., BUZETTI, S., FURLANI JÚNIOR, E. Adubação com NPK em coqueiro anão-verde (Cocos nucifera L.) - Atributos químicos do solo e nutrição da planta. Revista Brasileira de Fruticultura, Jaboticabal, v.27, n.1, p.115-119, 2005.

THIRY-CHERQUES, H.R. Saturação em pesquisa qualitativa: estimativa empírica de dimensionamento. Pesquisas de Marketing, Opinião e Mídia, São Paulo, v.3, n.3, p.20-27, 2009. 